\title{
Welding with high power fiber lasers - a preliminary study
}

\author{
L. Quintino***, A. Costa*, R. Miranda****, D. Yapp****,
}

\section{*IDMEC}

Address: Av. Rovisco Pais, 1049-001 Lisboa - Portugal

Telephone: 351218419616

Email: alex.costa@ist.utl.pt

**Instituto Superior Técnico, Secção de Tecnologia Mecânica

Address: Av. Rovisco Pais, 1049-001 Lisboa - Portugal

Email: lquintino@ ist.utl.pt

$* * *$ Universidade Aberta

Address: R. Escola Politécnica 147, 1269-001 Lisboa - Portugal

Telephone: 351213916434

Email: rmiranda@univ-ab.pt

\begin{abstract}
The new generation of high power fiber lasers presents several benefits for industrial purposes, namely high power with low beam divergence, flexible beam delivery, low maintenance costs, high efficiency and small implantation space. This paper presents preliminary results of weld beads produced on thick X100 pipeline carbon-steel plates with an $8 \mathrm{~kW}$ fiber laser. Weld bead geometry was evaluated and transition between conduction and deep penetration welding modes was investigated.
\end{abstract}

\section{Introduction}

The methods, processes and procedures for joining need to evolve at least as fast as the materials and the applications demand. Lasers are playing an important role in the joining of materials since the invention of high power solid state and gas lasers in 1964, namely, in these first years, for resistance trimming of electronic circuits till the introduction in the market of a reliable high performance laser in the late 70's, which allowed its application for welding of sheet metal parts.

The last decade has seen the rise of diode lasers and diode pumped solid state lasers. More recently high power diode pumped fiber lasers were developed. Fiber lasers have been stated to be a serious alternative to solid state and carbon dioxide lasers for different materials processing applications.

Fiber lasers were arisen in the early sixties and used widely at low power levels through out the 80's and the 90's as optical amplifiers. In 2000 the first $100 \mathrm{~W}$ fiber laser was launched. The first reports on the potential of these lasers in materials processing are very recent [1]. The multi-kilowatt range for materials processing with fiber laser is now possible with the recent commercialization of 7 to $10 \mathrm{~kW}$ power lasers.

These new lasers have multiple advantages, namely: the high efficiency, compared to lamp or diode pumped rod lasers; the compact design, which simplifies its installation; a good beam quality, due to the use of thin fibers, and thus small beam focus diameter; a robust setup for 
mobile applications. The scaling of the laser power is achieved by a modular design comprising several single mode lasers. The lifetime of the pumping diodes exceeds the expected lifetime of other diode pumped lasers, which leads to low costs of ownership.

The high power lasers can be used for deep penetration welding in a diversity of materials and constructions as the low wavelength that characterizes these lasers allows its absorption by almost all metals and alloys and the fiber delivery system provides the necessary flexibility on the positioning of the beam. Also high speed welding of sheet metal joints can surpass the productivities achieved with high power $\mathrm{CO}_{2}$ lasers.

The present paper presents a preliminary study of the influence of high power fiber laser welding parameters on weld bead geometrical characteristics.

\section{Laser characteristics}

In a fiber laser, the active medium is the core of the fiber doped with a rare earth. Most commonly, this is a single-mode fiber laser made of silica. The pump beam is launched longitudinally along the fiber length and it may be guided by either the core itself, as occurs for the single-mode lasers or by an inner cladding around this core (double-clad fiber laser) as shown in Figure 1.
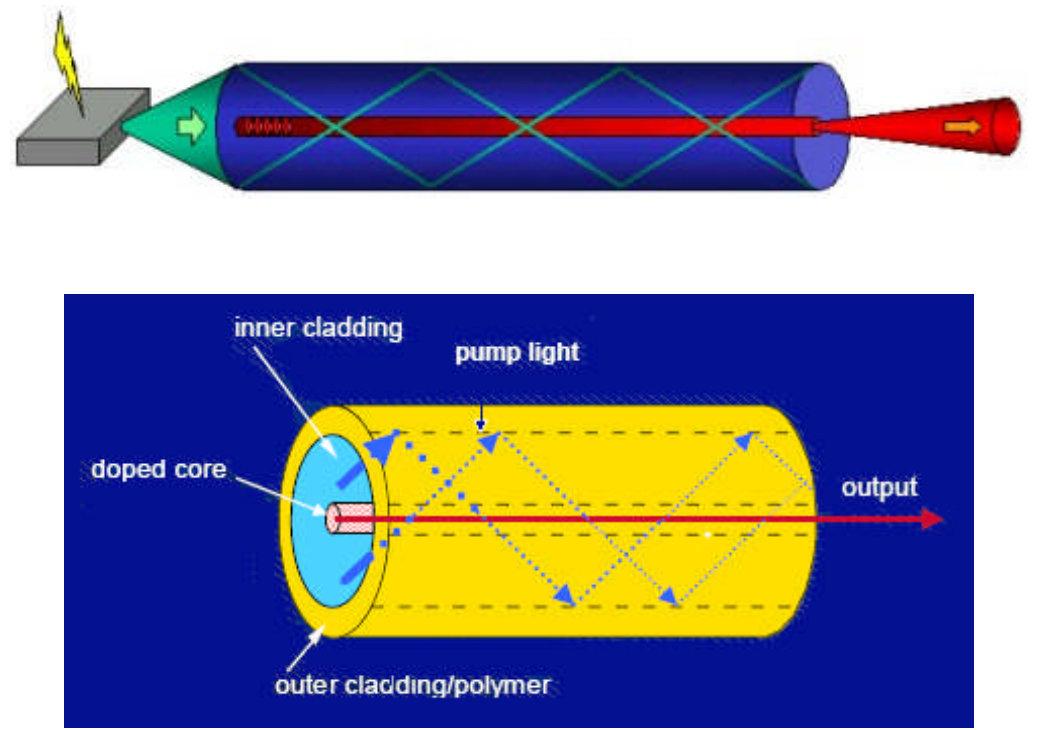

Fig. 1- Double-clad fiber laser [2]

In a fiber laser, a silica "active" fiber doped with erbium, ytterbium, neodymium or thallium, is exited by a diode laser source. Two Bragg gratings, which reflect a predetermined narrow or broad range of wavelengths of light incident on the grating, while passing all other wavelengths of the light are written into the fiber generating the laser emission and resulting in an efficient, compact laser source with high beam quality (figure 2). The incident light in the inner cladding penetrates, being catch in the core, where doping elements, causing a high refraction coefficient, are present. The outer cladding is made of glass or polymeric material, with low refraction coefficient, in order to prevent the signal attenuation. 


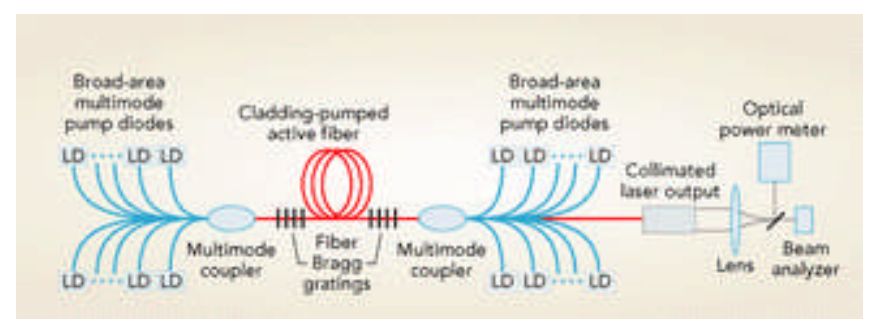

Fig. 2 - Fiber laser pumping schematic [3]

The high power fiber lasers in the market are based on active fibers and a patented pumping technique that allows the utilization of broad area multimode diodes rather than diode bars. A device made from coils of ytterbium-doped multi-clad fiber with an emission wavelength of 1.07 to 1.08 microns is used. Alternately, it may be thallium doped with a wavelength of 1.8 to 2.0 microns or erbium doped with a wavelength of 1.54 to 1.56 microns (Figure 3 ). The diode pumped energy is delivered to the active medium via multimode fibers that are spliced to the multi-clad coil. The laser cavity is created directly in the active fiber. The laser emission exits the fiber laser through a passive single-mode fiber, typically, with a core diameter of 6 microns [3].

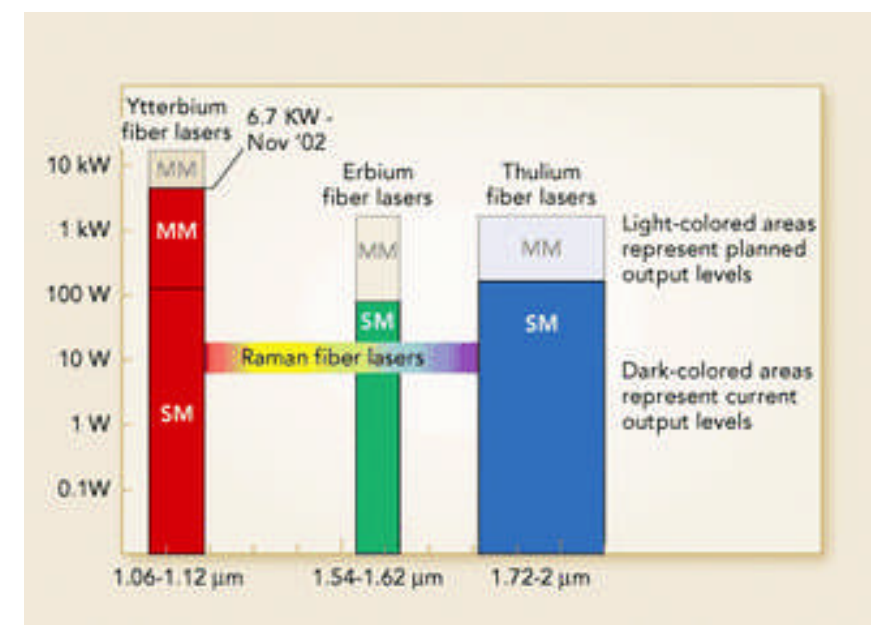

Fig. 3 - Fiber laser spectral ranges. Solid areas represent current output levels and shaded areas represent planned output levels [3]

The resulting laser beam is essentially diffraction limited and, when outfitted with an integral collimator, produces a beam that is extremely parallel. For example, the 100 -watt single-mode fiber laser has a full angle divergence of 0.13 milliradians at half angle when collimated to 5 $\mathrm{mm}$ diameter. A 1-kilowatt unit would be made up of 10 individual fiber lasers integrated into a common cabinet. Although the beam is no longer single-mode, the resulting $\mathrm{M}^{2}$ of $7-10$ is better than high-power solid-state lasers. The beam from a $6 \mathrm{~kW}$ fiber laser can be delivered via a 200 to 300 micron fiber. The ytterbium fiber laser has a wall plug efficiency of 16 to 20 percent. Erbium and thulium fiber lasers demonstrate lower wall plug efficiency, but they are still more efficient than typical YAG lasers. 


\subsection{Beam Quality}

When processing materials with a high power beam laser, the ability to focus the beam is absolutely critical, because good focusability means a smaller spot size and better depth of field. When focusability is good, focusing optics with a longer focal length can be used, which in turn leads to a large work clearance. The focusability of a laser beam is often referred to as the beam quality.

Different variables are used to describe the beam quality. The beam quality of a $\mathrm{CO}_{2}$ laser is usually indicated by the beam propagation factor $\mathrm{k}$, or the beam parameter product (BPP) for an Nd:YAG laser. An alternative way to gain synthetic information on the overall beam quality relies on the definition of the $\mathrm{M}^{2}$ factor which allows the detection of beam profile deviations from the Gaussian ideal shape.

The beam parameter product (BPP) can be defined as follows:

$$
B P P=\alpha . \omega_{0} \quad(\text { eq. } 1)
$$

With $\omega_{0}$ being the radius of the beam waist and $\alpha$, the divergence angle.

The beam quality $\left(M^{2}\right)$ can be expressed by:

$$
\left.M^{2}=\alpha \omega_{0} \frac{\pi}{\lambda} \quad \text { (eq. } 2\right)
$$

Where $\lambda$ is the laser radiation wavelength.

Relating the beam quality and the beam parameter product:

$$
M^{2}=B P P \frac{\pi}{\lambda} \quad \text { (eq. 3) }
$$

Considering the beam propagation factor $(\mathrm{k})$ in equation 4 :

$$
k=\frac{\lambda}{\pi} \frac{1}{\alpha \omega_{0}}
$$

Then the beam quality can be expressed by equation 5 , where:

$$
M^{2}=\frac{1}{k}
$$

The values are mathematically related and can be compared to each other. The three variables are suitable for comparing lasers of the same wavelength. The beam parameter product (BPP), is particularly suited for comparing the laser beams focusability, since the influence of the wavelength on the focusing diameter is already accounted for in BPP.

The quantity $\mathrm{M}^{2}$ is a numerical expression of the beam quality, with 1 being a perfect Gaussian beam and higher values indicating poorer quality. The usefulness of low-quality beams, $\mathbf{M}^{2} \geq 80$ is almost restricted to welding, though laser percussion drilling of holes of a few hundred micrometers in diameter and a few millimetres deep in gas turbine blades requires $\mathrm{M}^{2}$ of about 25 to provide a low taper and a small hole size [4]. High power fiber lasers present non Gaussian transverse electromagnetic modes (Fig.4) and thus high $\mathrm{M}^{2}$ values. 


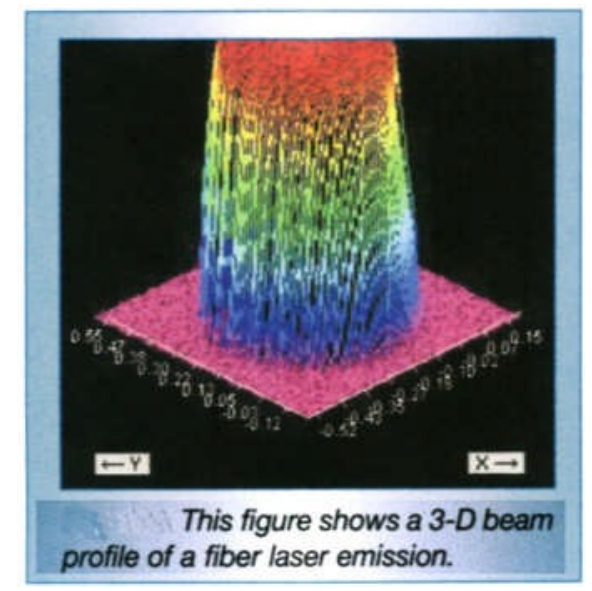

Fig. 4 - Profile of a fiber laser emission [5]

Wavelengths also provide information about beam quality as, at shorter wavelengths, the more energetic photons can be absorbed by a greater number of bound electrons and so the reflectivity falls and the absorption of the surface increases (fig. 5).

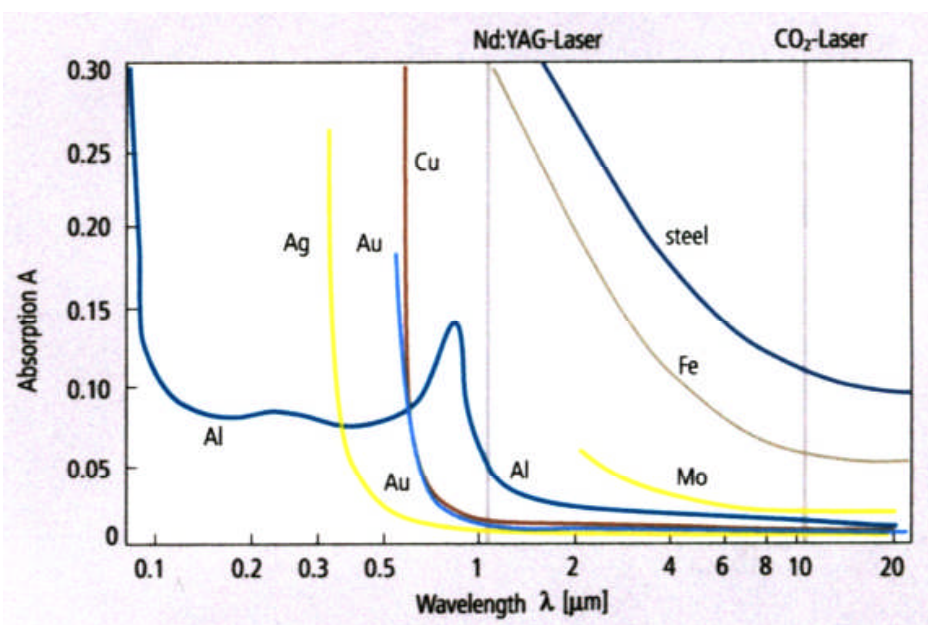

Fig. 5 - Absorption of a number of metals as a function of laser radiation wavelength [6]

Beam divergence and focal spot size needs to be considered in all applications as these play an important role in the quality of the results achieved in laser welding, e.g. small beam divergence and focal spot diameters lead to welds with higher penetration and smaller width for a given welding speed.

\section{Fiber laser benefits}

Fiber laser technology offers several benefits to the industrial user. The footprint of a $4 \mathrm{~kW}$ fiber laser unit is $0.5 \mathrm{~m}^{2}$ versus $11 \mathrm{~m}^{2}$ for a conventional lamp-pumped Nd:YAG, and there is no requirement for a chiller, once they are air refrigerated, being the heat dissipated by the overall fiber length. The dimensions of $8 \mathrm{~kW}$ fiber laser are $1.5 \times 0.8 \times 1.5 \mathrm{~m}$, approximately. They are essentially maintenance free during their entire lifetime because there is no need to replace flash lamps or diodes. The high electrical efficiency greatly reduces operating costs. Better beam quality, with very low divergence, allows the user to produce spot diameters 
substantially smaller than conventional lasers producing high fluence and/or longer working distances. A 1 kilowatt laser can be focused to 50 microns spot size with a $100 \mathrm{~mm}$ focal length lens. An $8 \mathrm{~kW}$ can be focused to a spot size of $0.6 \mathrm{~mm}$ with a $250 \mathrm{~mm}$ focal length lens.

The cost for fiber laser technology up to $1 \mathrm{~kW}$ output power is below or comparable with lamp-pumped YAG lasers. The cost of a fiber laser greater than 1 kilowatt is higher. However, when all factors are accounted for these lasers, namely, floor space, chillers and maintenance, they should be more cost effective than equivalent power rod-type Nd:YAG lasers.

These lasers have operated flawlessly on a multiple-shift basis, demonstrating their reliability and providing performance data only possible with much larger lasers. A $2 \mathrm{~kW}$ unit has been lap welding $1.2 \mathrm{~mm}$ thick, zinc-coated automotive steel at $5 \mathrm{~m} / \mathrm{min}$. The quality and performance is comparable to a $4 \mathrm{~kW}$ lamp-pumped rod type $\mathrm{Nd}$ :YAG laser [3]. A $2 \mathrm{~kW}$ fiber laser, with a 300 micron final fiber diameter, cuts $4 \mathrm{~mm}$-thick coated steel, at a rate of 10 $\mathrm{m} / \mathrm{min}$, with clean sharp edges. The maximum cutting speed attained is $16 \mathrm{~m} / \mathrm{min}$ [3]. High quality micro-welding is already achieved with single-mode (SM) fiber lasers for stainless steels foils of 10 to $100 \mu \mathrm{m}$, with high speed, using an ultra-fine keyhole welding mode [7]. Perforation and cutting of natural stone is being performed in USA with high expectations generated by a study on the potential use of these lasers [8]. Miyamoto et al. [9] studied stainless steel micro-welding, in specimens from 10 to $100 \mu \mathrm{m}$, with a fiber laser doped with ytterbium, with a power between 40 and $200 \mathrm{~W}$ and a travel speed of $1500 \mathrm{~mm} / \mathrm{s}$, with good results. In the electronic industry, micro-welding and cutting is already performed. For the automobile industry, automated welding, marking and cutting are realised. Aluminium and titanium welds are also performed in the aerospace industry. Marking, cutting and microwelding are undertaken in medical equipments [10]. The Bremer Institute in Germany (BIAS) studied fiber laser aluminium welding with excellent results for the AA6056 alloy, with $6 \mathrm{~mm}$ thickness, a power of $6.9 \mathrm{~kW}$ and a velocity of $50 \mathrm{~mm} / \mathrm{s}$ [11].

\section{Experimental Procedure}

The high power fiber laser used it was an IPG YLR-8000 equipment with a maximum output power of $8 \mathrm{~kW}$, an emission wavelength of $1070 \mathrm{~nm}$, a spot focus diameter of $0.6 \mathrm{~mm}$ with a focal length lens of $250 \mathrm{~mm}$ and a beam parameter product (BPP) of $16 \mathrm{~mm} . \mathrm{mrad}$. The system comprises a feeding fiber of $200 \mu \mathrm{m}$ core diameter and a process fiber with $300 \mu \mathrm{m}$. Figure 6 shows a 3D presentation of the beam shape and a single plan view.

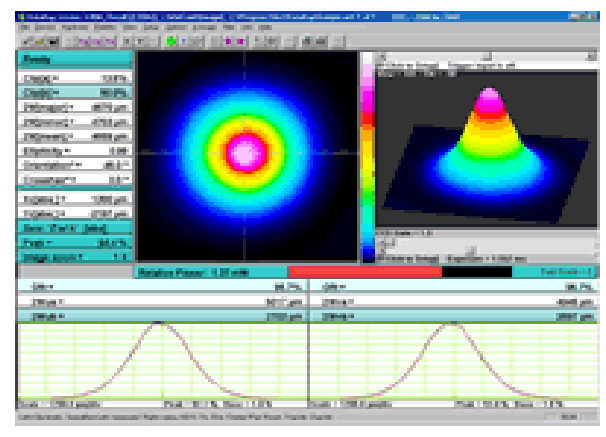

Fig. 6 - Laser beam characteristics [12] 
The experimental set up adopted is shown in figure 7. The process fiber is mounted on a Fanuc M-710iB/45T robot via a special device. The robot end-effector holds the laser head perpendicular to the workpiece and has the capability of moving in $3 \mathrm{D}$ work space.

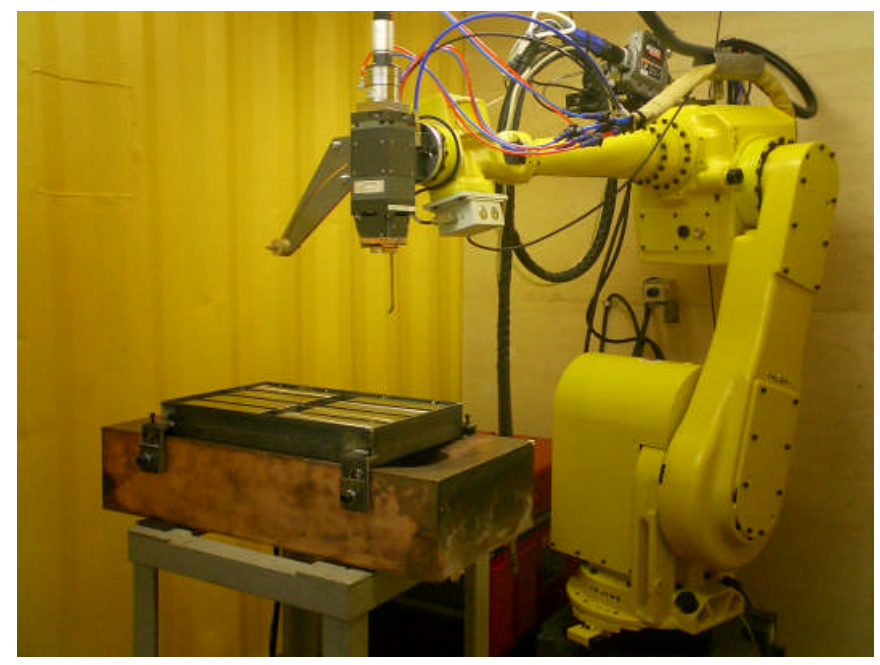

Fig. 7 - Experimental set-up

A set of experiments was designed with four levels of laser power (from 2000 to $8000 \mathrm{~W}$ ) and six levels of travel speed (from 30 to $800 \mathrm{~cm} / \mathrm{min}$ ). The focal point was kept constant on the specimen surface (f.p.p. $=0 \mathrm{~mm}$ ). Argon was used as assist gas at a flow rate of $11 \mathrm{l} / \mathrm{min}$. All other processing parameters were kept constant.

The base material used for this study was the API X100 low carbon steel, $19 \mathrm{~mm}$ thick, for pipeline applications. Chemical composition and mechanical properties are shown in Tables 1 and 2. The experimental results were analysed on the basis of the relationships between process parameters and weld bead shape and dimensions. Melting efficiency was also analyzed. The specimen's surfaces were prepared and cleaned to assure that all samples presented the same surface conditions with an homogeneous finishing.

\begin{tabular}{|c|c|c|c|c|c|c|c|c|c|c|}
\hline $\mathrm{C}$ & $\mathrm{Mn}$ & $\mathrm{Ni}$ & $\mathrm{Cu}$ & $\mathrm{Mo}$ & $\mathrm{Cr}$ & $\mathrm{Si}$ & $\mathrm{V}$ & $\mathrm{Nb}$ & $\mathrm{Ti}$ & $\mathrm{Al}$ \\
\hline 0.025 & 1.98 & 0.48 & 0.46 & 0.43 & 0.42 & 0.2 & 0.07 & 0.05 & 0.015 & 0.006 \\
\hline
\end{tabular}

Table 1 - X100 steel chemical composition (wt\%)

\begin{tabular}{|c|c|c|}
\hline $\mathrm{E}[\mathrm{GPa}]$ & $\sigma_{\mathrm{c}}[\mathrm{MPa}]$ & $\sigma_{\mathrm{R}}[\mathrm{MPa}]$ \\
\hline 210 & 735 & 886 \\
\hline
\end{tabular}

Table 2 - X100 steel mechanical properties [13]

After welding, specimens were cut from transverse sections at the mid-length position of the welds and the cut surfaces prepared for metallographic inspection by polishing and etching using a 5\% nital solution to display bead shape and microstructure. The bead shape measurements were made using an optical perfilometer with an image analysis system. 


\section{Results}

In figure 8 it can be observed a photomacrograph of a specimen welded by high power fiber laser in API X100 low carbon steel showing deep penetration welding mode.

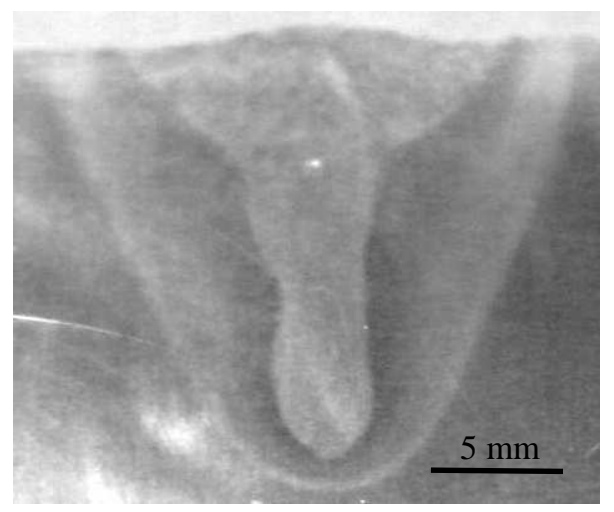

Fig. 8 - Photomacrograph of fiber laser weld on steel plate, showing deep penetration $(P=6000 \mathrm{~W}, v=50 \mathrm{~cm} / \mathrm{min}, E=720 \mathrm{~J} / \mathrm{mm})$

Figure 9 shows a plot of the results for the penetration attained as a function of the heat input. It can be observed that for low heat input (between 10 and $100 \mathrm{~J} / \mathrm{mm}$ ) the penetration achieved was very low and the conduction mode prevailed. For higher heat inputs (from 600 to $1000 \mathrm{~J} / \mathrm{mm}$ ) the penetration increased significantly and a deep penetration mode was observed [14].

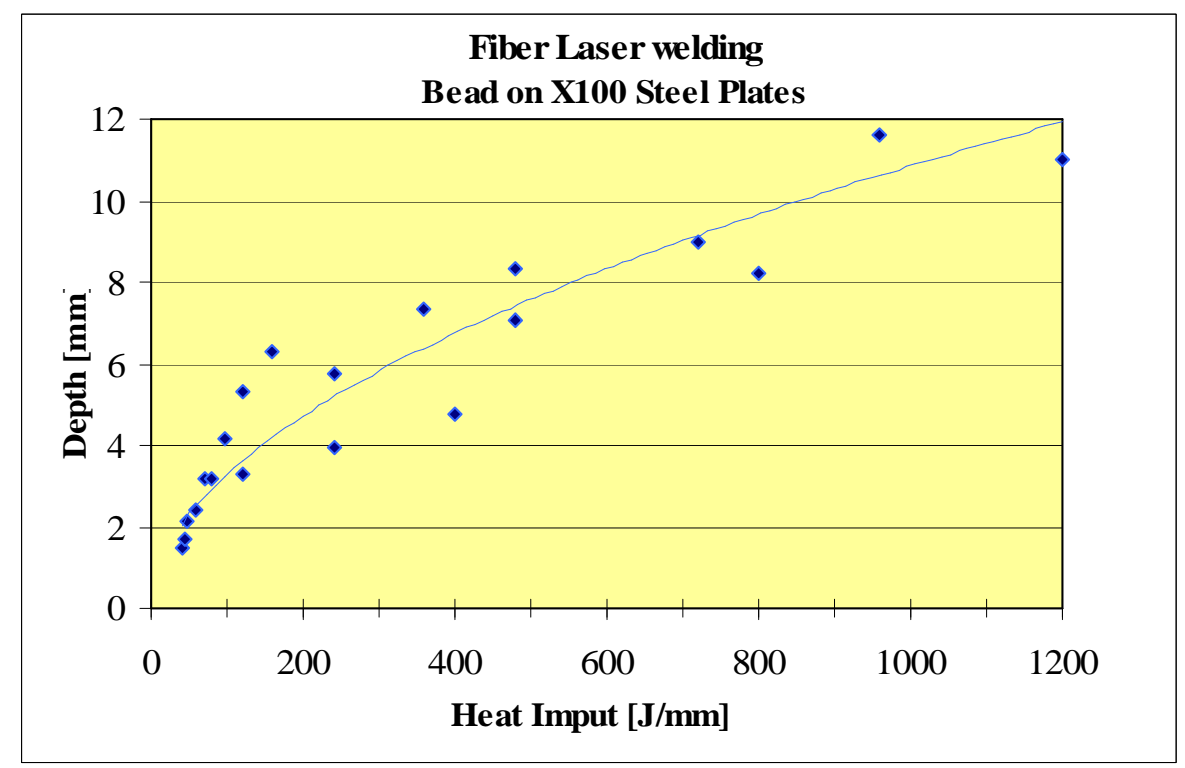

Fig. 9 - Penetration versus heat input for Fiber laser welding

Analysing the behaviour of weld beads penetration as a function of laser power and welding speed represented in figures 10 and 11, respectively, it can seen that weld depth follows the usual trends observed in laser welding. That is, the weld depth has an almost direct linear relationship with the laser power and decreases exponentially with the welding speed [6]. 


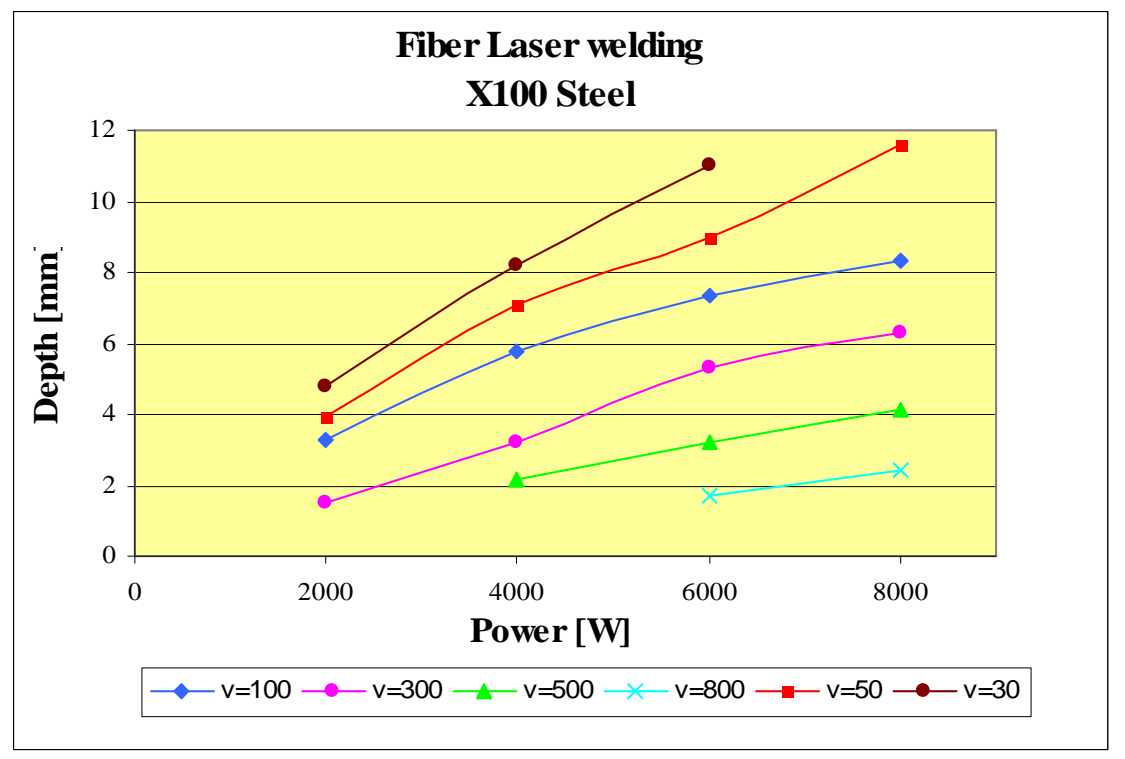

Fig. 10 - Penetration versus laser power for Fiber laser welding (for constant travel speeds in $\mathrm{cm} / \mathrm{min}$ )

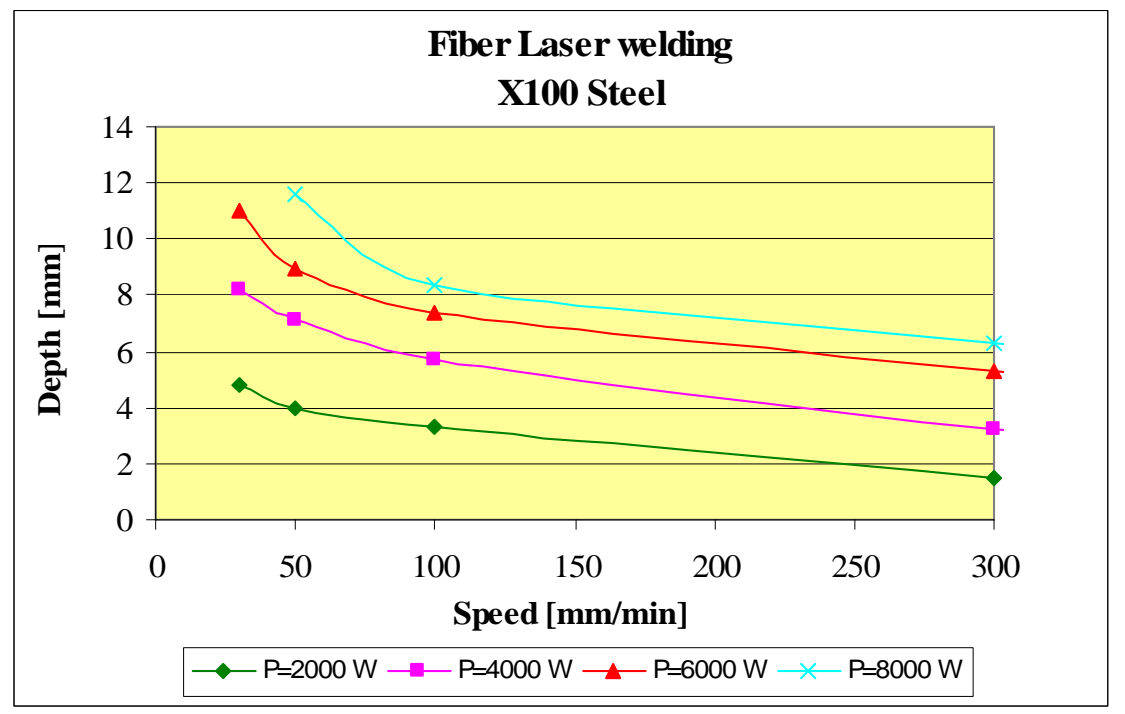

Fig.11 - Penetration versus welding speed for Fiber laser welding (for constant power levels)

The high power lasers allow high welding speeds due to the high energy density delivered. When coupling the laser beam onto a surface, part of the radiation is absorbed by the material and part is lost by reflection, radiation, conduction and plasma absorption [15]. If the laser beam is defocused and the heat input is very low, conduction mode welding is the main mechanism involved which results in high conduction losses, low penetration achieved and poor process efficiency. Typically, conduction weld beads present a semi-spherical geometry with penetration lower then the bead width. If the laser beam irradiates the workpiece with high energy density (typically $>10^{6} \mathrm{~W} / \mathrm{cm}^{2}$ ) a keyhole is formed, which enables the laser beam to penetrate deeply and deep penetration mode mechanism becomes predominant, 
increasing welding efficiency. Deep penetration welds present usually "finger prints" geometry (conical to cylindrical) as the one observed in figure 9.

Melting efficiency was analysed to observe the loss of energy in the first's experiments undertaken with the purpose to improve the welding process in the subsequent set of weldments. To analyse this factor [14] it was considered that full efficiency occurs when all the power $(\mathrm{P})$ delivered is used to melt a unit of material volume $(\mathrm{V})$, the weld bead has a cylindrical shape and no losses take place:

$P=V E$

(eq. 6)

Where "P" the laser power [W]. "V" the volume melted by unity of time $\left[\mathrm{m}^{3} / \mathrm{s}\right]$. "E" is the energy required for melting a volume unit $\left[\mathrm{J} / \mathrm{m}^{3}\right]$.

Considering " $\rho$ " the density $\left[\mathrm{Kg} / \mathrm{m}^{3}\right]$, "Cp" the specific heat $[\mathrm{J} / \mathrm{Kg} \mathrm{K}]$, "T" the temperature $[\mathrm{K}]$ and "H" the melting latent heat $[\mathrm{J} / \mathrm{Kg}]$, power becomes:

$P=V \rho\left[c_{p}(\Delta T)+H\right] \quad$ (eq.7)

Multiplying the travel speed by the weld bead width and depth, volume is atained, with " $v$ " the velocity $[\mathrm{m} / \mathrm{s}]$, "b" the weld bead width $[\mathrm{m}]$ and " $\mathrm{h}$ " the weld bead penetration $[\mathrm{m}]$

$P=v b h \rho\left[c_{p}\left(T_{m}-T_{0}\right)+H\right]$

If the specific heat is put in evidence, then

$P=v b h \rho c_{p}\left(T_{m}-T_{0}+\frac{H}{c_{p}}\right)$

Multiplying and dividing the first term by the diffusivity $\left(\alpha\left[\mathrm{m}^{2} / \mathrm{s}\right]\right)$, eq. 9 can be rewritten as:

$P=\frac{v b}{\alpha} h \rho c_{p} \alpha\left(T_{m}-T_{0}+\frac{H}{c_{p}}\right) \quad$ (eq.10)

Since the thermal conductivity is defined by $K=\rho c_{p} \alpha[\mathrm{W} / \mathrm{mK}]$, then

$P=\frac{v b}{\alpha} h K\left(T_{m}-T_{0}+\frac{H}{c_{p}}\right)$

If,

$T_{m}-T_{0}+\frac{H}{c_{p}}=d$

then

$P=\left(\frac{v b}{\alpha}\right)(h . K . d)$

reordening equation 13 :

$\frac{v b}{\alpha}=\frac{P}{h K d}$ 
The steel thermal properties are displayed on table 3. Due to the lack of data available on the thermal behaviour of API X100 steel, the properties used where taken from a steel with the same carbon equivalent $(\mathrm{Ceq}=0.32)$ and a similar manganese content.

\begin{tabular}{|c|c|c|c|}
\hline $\mathrm{K}$ & $\rho$ & $\mathrm{c}_{\mathrm{p}}$ & $\mathrm{H}$ \\
\hline $48.2 \mathrm{~W} / \mathrm{mK}$ & $7.85 \times 10^{3} \mathrm{Kg} / \mathrm{m}^{3}$ & $456 \mathrm{~J} / \mathrm{KgK}$ & $274052 \mathrm{~J} / \mathrm{Kg}$ \\
\hline
\end{tabular}

Table 3 - X100 steel Thermal Properties [16]

Using equation 14, melting efficiency was computed. Figure 12 shows the relationship between welding speed parameter $(\mathrm{vb} / \alpha)$ and laser power parameter $(\mathrm{P} / \mathrm{hKd})$. When there is a full melting efficiency, these parameters present the same value $(y=m . x$, with $m=1)$. The dashed line was interpolated from the welding data obtained with fiber laser and the determined slope is about 0.66 which corresponds to an average efficiency of $66 \%$. A good melting efficiency is attained, when compared with conventional lasers. The energy loss is mainly due to conduction losses, which is an important welding mode observed.

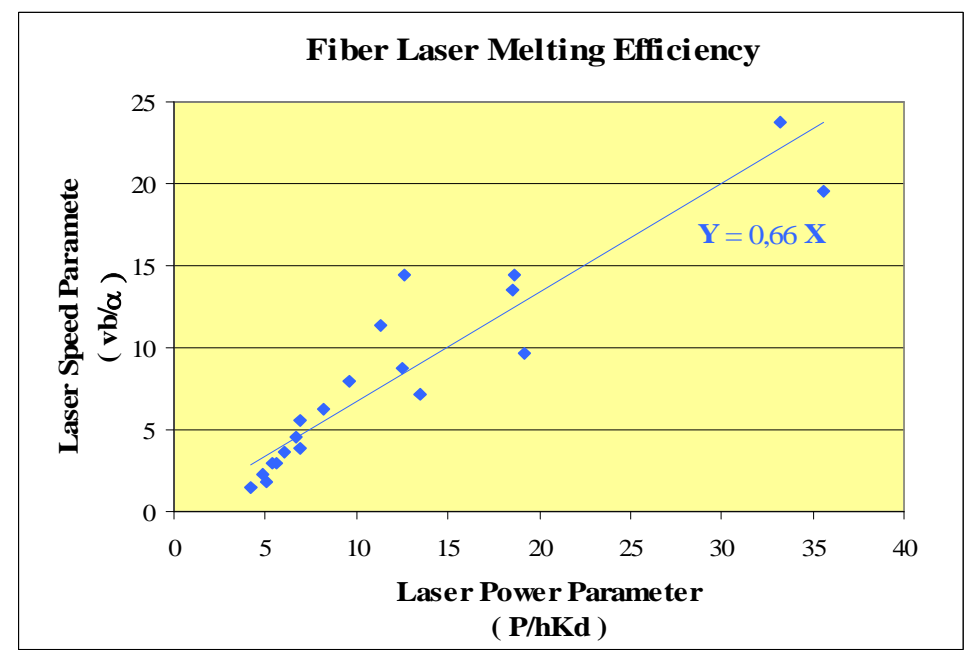

Fig. 12 - Fiber Laser Melting Efficiency

Heat input and power density are very important parameters to attain full penetration. Several authors consider power density as the main factor for the transition between conduction mode and keyhole welding, however, a coupled analysis is needed. In order to relate both parameters, beam power was divided by the interaction area, giving the power density, which is then divided by the travel speed, giving the energy by volume of interaction $(\varepsilon-$ specific energy $\left.\left[\mathrm{J} / \mathrm{mm}^{3}\right]\right)$.

Figure 13 shows the penetration evolution as a function of " $\varepsilon$ ". It can be noticed a variation in the slope of the dashed line. This corresponds to a transition of welding mode from conduction (at low energy values) to deep penetration (above $400 \mathrm{~J} / \mathrm{mm}^{3}$ ).

If the aspect ratio (a.r. - aspect ratio - bead depth / bead width) is considered (figure 14) it can be stated that for low specific energies, "a.r." is lower than 1.5 which means that conduction mode was the predominant mechanism. The aspect ratio increases with " $\varepsilon$ " and for $\varepsilon>400$ $\mathrm{J} / \mathrm{mm}^{3}$, deep penetration becomes the main welding mode. 
From figures 13 and 14, it can be identified the transient heat input from conduction mode to keyhole welding mode. It is observed that for an heat input above $600 \mathrm{~J} / \mathrm{mm}$ and a specific energy of $400 \mathrm{~J} / \mathrm{mm}^{3}$, deep penetration mode becomes predominant, the aspect ratio increases significantly and the weld bead exhibits a conical geometry instead of the semi-spherical geometry typical for conduction welds mode.

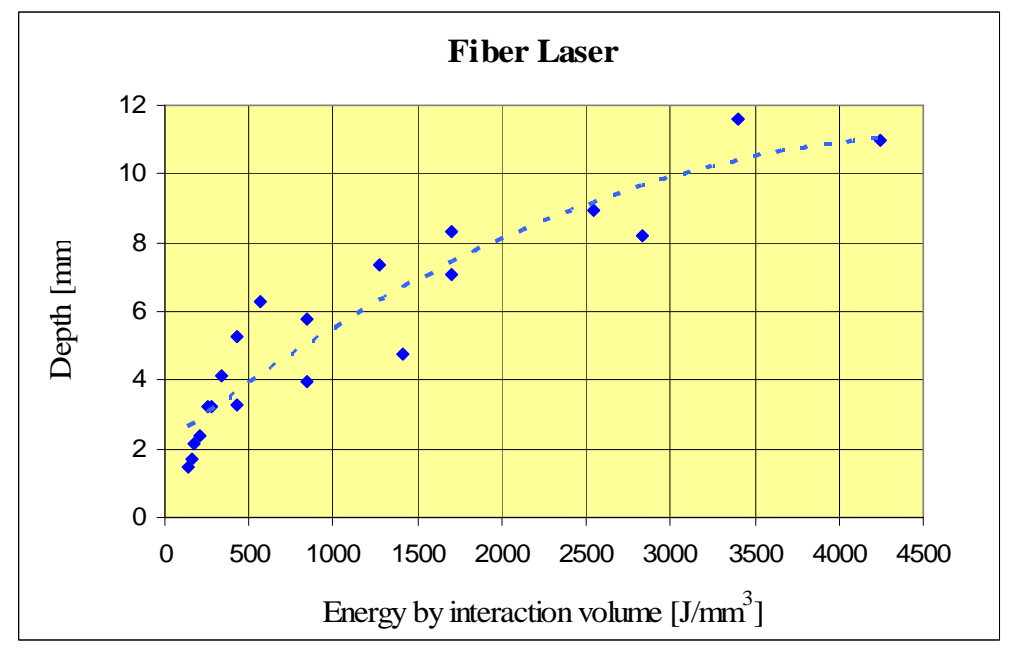

Fig. 13 - Penetration as function of specific energy for fiber laser welding of X100 steel

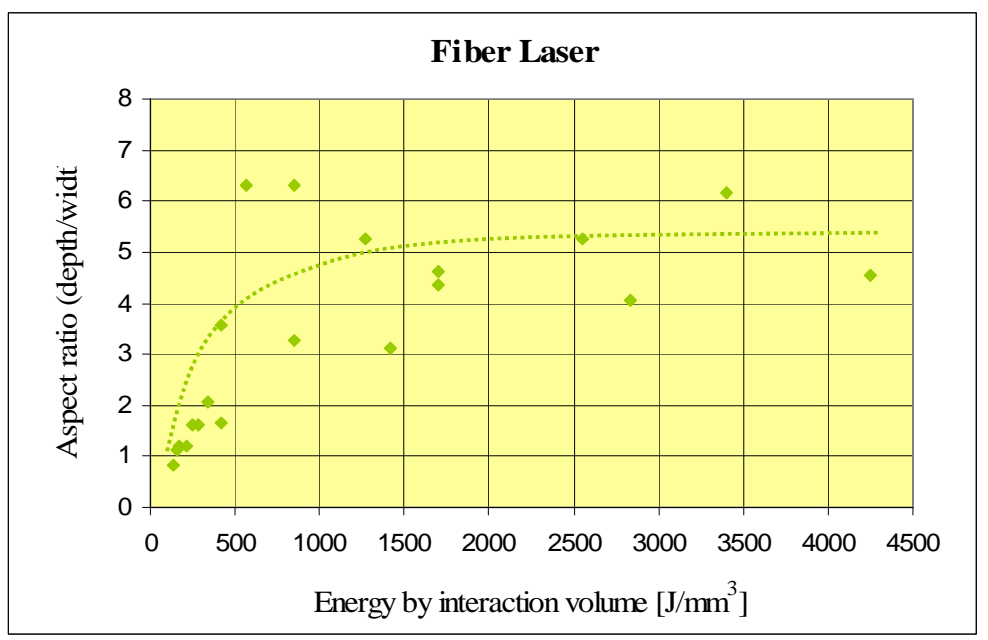

Fig. 14 - Aspect ratio (depth/width) as function of specific energy for fiber laser welding of X100 steel

\section{Conclusions}

From this first set of laser experiments, performed with a recently installed fiber laser of 8 $\mathrm{kW}$, it is possible to withdraw the following general conclusions:

- Weld beads present a finger print format with large beads width at the top, due to focal point position placed on the surface.

- It is possible to identify the transient heat input from conduction mode to keyhole mode welding using a coupled analysis between heat input and power density. 
- A high melting efficiency was observed, when compared with conventional lasers. The energy losses are mainly due to conduction mode welding, which is the main mechanism observed near the surface.

Further experimentation is being carried out using procedures derived from this first study, mainly optimizing the focal point position and shielding gas, in order to limit the bead width near the surface and to achieve higher penetrations and productivity rates.

\section{References}

1. Hill P. "Fiber laser hits 2kW record mark", Opto and Laser Europe (OLE),July/august 2002,pp.9

2. A new Generation of Lasers for Industrial Applications: Fiber Lasers (in http://www.zugo.com.sg)

3. B. Shiner, "High power fiber lasers impact material processing", Industrial Laser Solutions, February 2003 , pp 9-11 (in http://ils.pennnet.com)

4. Luigi Zeni, Stefania Campopiano, Antonello Cutolo, Giuseppe D'Angelo, "Power semiconductor laser diode arrays characterisation", Optics and Lasers in Engineering, vol. 39, issue 2, Feb. 2003, pp 203-217

5. ------

6. W.M. Steen,'Laser Material processing”, Ed. Springer Verlag, $3^{\text {rd }}$ edition, 2003

7. I. Miyamoto, S. Park, T. Ooie "Ultrafine keyhole welding processes using singlemode fiber laser" LMP Section A, pp.203-212

8. B.C. Gahan "New high-power fiber laser enables cutting edge research", Laser Technology, Winter 2004, pp.29-31

9. I. Miyamoto, T. Kosumi, P. Seo-jeong, H. Huragishi, K. Watanabe, T. Ooie, "Applications of single mode fiber lasers to novel micromachining", Proc. LMP 2004, Osaka, May 2004

10. B. Shiner, IPG Photonics Inc., "Fiber Lasers for Material Processing", LIA Today, Abril 2004

11. M. Grupp T. Seefeld F. Vollertsen, BIAS, Bremen, Germany, "Industrializing fiber lasers", Industrial Laser Solutions, March 2004

12. ------

13. S. Deshimaru, K. Takahashi, S. Endo, J. Hasunuma, K. Sakata, Y. Nagahama, "Steel for production, transportation and storage of Energy", JFE Technical Report, No2, March 2004

14. John F. Ready, "LIA Handbook of Laser Material Processing”, Magnolia Publishing, Inc, 2001

15. Y. Arata, N. Abe, "Fundamental Phenomena CO2 Laser Welding", Transactions of JWRI, Vol. $1 \mathrm{n}^{\circ} 1,1985$

16. Colin J. Smithells, "Smithells Metals Reference Book", $8^{\text {th }}$ Edition, ButterworthHeinemann, 2003

\section{Acknowledgements}

The authors wish to thank the Welding Research Laboratory of Cranfield University, for the experimentation undertaken. 